\title{
Free-running building temperature and HVAC climatic suitability
}

\author{
Cristian Ghiaus \\ Laboratoire d'Étude des Phénomènes de Transfert Appliqués au Bâtiment, \\ Université de La Rochelle, Av. M. Crépeau, 17000 La Rochelle, France
}

Tel.: 00335 46457259; fax: 0033546458241

E-mail address: cristian.ghiaus@univ-lr.fr 


\title{
Free-running building temperature and HVAC climatic suitability
}

\begin{abstract}
Decisions taken in the early stages of architectural design have an important impact on energy demand and efficiency. In this design phase, architects and engineers need to manipulate common concepts that reveal the influence of building, comfort criteria, and climate on energy consumption. Such a concept is the indoor temperature of the free-running building, which, combined with comfort criteria and climate, allows to assess the relative weight of heating, ventilation and air conditioning systems in energy budget. Based on this concept and on the probabilistic distribution of the outdoor air temperature, it was developed a method that indicates the heating and cooling needs, and gives a measure of the energy saved for cooling when ventilation is used. This method also gives the load for which the mechanical systems should be designed to obtain maximum efficiency and shows the feasibility of stack-induced natural ventilation. Weather data needed for this method are available in public domain from satellite investigation. The method can be applied when buildings similar to existing ones are constructed in a new location, when existing buildings are retrofitted or when completely new buildings are designed.
\end{abstract}

Keywords: degree-hour, climate, building design, energy demand and efficiency

\section{Introduction}

Architectural design has an important impact on energy demand and efficiency. Decisions taken in the early stages of building design influence and restrict the solutions for heating, ventilation and air conditioning. In the initial phase of design, architects and engineers need to analyse options with methods for which data gathering, input preparation, calculations and output analysis take a short time. Although these methods do not need to be very accurate, they should allow the choice of the correct heating, ventilation, and air conditioning (HVAC) solution and should not need so many vaguely defined options that different designers would obtain completely different results [1]. It is preferable that the concepts involved have a common meaning for both architects and engineers, are easily identifiable, and show the effect of design solutions on energy consumption.

Most currently available building simulation programs can solve only closed problems. They respond to a "what happens if" question: what will be the result if this parameter has this value. It is the principle of detailed building simulation programs, like DOE-2, BLAST, COMIS and TRNSYS, that are useful for performance evaluation in the final phase of design. These programs can help the user to estimate the annual energy consumption of a building and its HVAC system but cannot suggest design strategies to improve the building performance [2]. However, in conceptual and preliminary design stages, the problem is open. We need the answer to a "what to do" question such as: Should we design the building to use natural ventilation for cooling or should we consider an air conditioning system? Is it worth to increase the thermal mass? What will be the influence of comfort criteria? How to avoid poor 
energy performance due to excessive part-load operation of heating or cooling systems? In early stages of design, when architects take decisions that implicitly answer these questions, they have little or no technical support. Engineers are often brought into the project after the building form, fenestration, orientation and construction materials were decided. It is important to have a tool that can respond to an open problem in the conceptual stage of design. One approach for assessing climatic suitability of natural ventilation in office buildings is based on balance point temperature. This method is suitable for volume dominated commercial buildings, for which thermal loss due to the air change is much more important than the loss through the building envelope [3].

The building energy performance and HVAC solution depends on three factors: thermal characteristics of the building, comfort criteria and climate. The first factor may be synthesized by the indoor temperature of the free running building, which is shifted from the value of the outdoor temperature with a difference that depends on the heat loss, ventilation rate, solar and internal gains, thermal mass and occupancy. This difference may be easily measured in existing buildings, or estimated for new ones. The second factor, the thermal comfort, has a neutral zone that varies with the mean outdoor temperature. This zone is larger in buildings that use natural ventilation as compared with those that have air-conditioning systems installed. Finally, the climate may be characterised by the frequency distribution of the outdoor temperature. Hence, climate suitability of HVAC systems may be assessed as a function of the indoor temperature of the free-running building, thermal comfort and monthly and hourly probabilistic distribution of outdoor air temperature. This method may use global climatic data obtained by satellite measurements and available in public domain.

\section{Method}

Climatic suitability of a HVAC system is a measure of energy needed for heating and mechanical cooling and of the energy saved for cooling when ventilation is used. The climate should be considered in relation with the building thermal behaviour and the anticipated thermal comfort. The presence of driving forces for natural ventilation (wind and buoyancy) is also important. The method proposed hereafter considers these aspects, apart from the wind.

First, the indoor temperature of the free running building, the adaptive comfort, and the frequency distribution of the outdoor air temperature are discussed. Then, the frequency distribution of degree-time is derived for heating and cooling. Finally, the applicability of ventilation for cooling and the availability of buoyancy forces for natural ventilation are presented.

\subsection{Indoor temperature of a free-running building}

A free-running building does not make any use of mechanical heating or cooling. Its indoor temperature, $T_{f r}$, depends on the outdoor temperature and the total heat gains (from sun, occupants, lights and so forth). The indoor temperature of the free-running building may be used instead of balance point temperature in energy estimation methods such as degree-days or bin methods. The balance point temperature is defined as the outdoor air temperature at which the total heat gains equal the total loss. For this temperature, the building, having a specified indoor air temperature, is in thermal balance with its environment when the heating or cooling system is not used [1]. The free-running temperature has an equivalent definition: 
it represents the indoor temperature of the building in thermal balance with the outdoor environment when neither heating nor cooling is used. Furthermore, we will consider that the free-running temperature is defined for the minimum ventilation rate needed for indoor air quality, which implies that the building is tight. With these assumptions, it may be accepted that, for a given month of the year, the indoor temperature of the free-running building is a function of the hour of the day (Fig. 1).

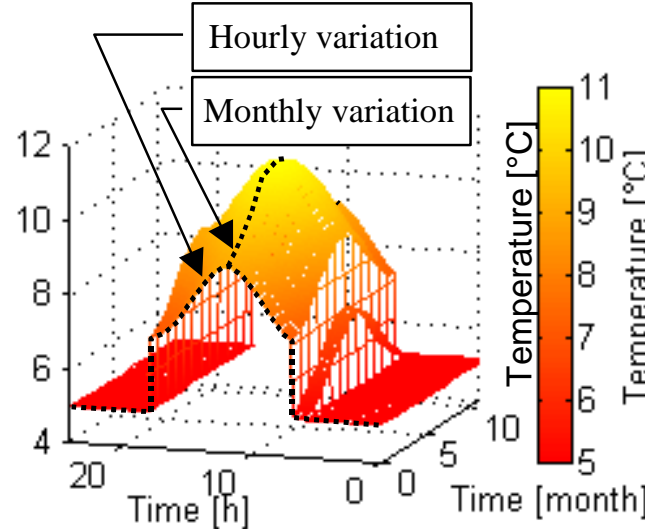

(a)

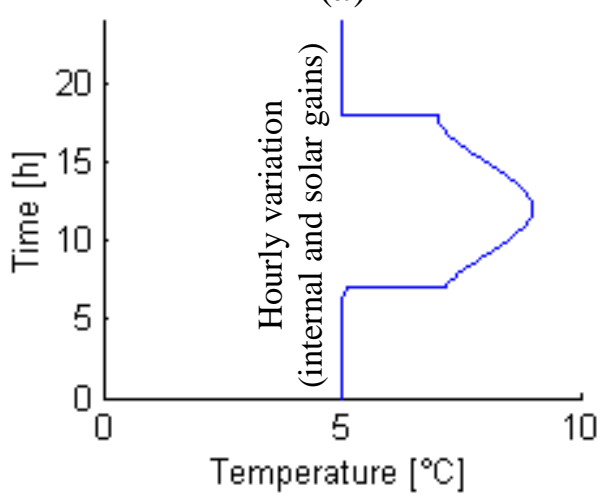

(c)

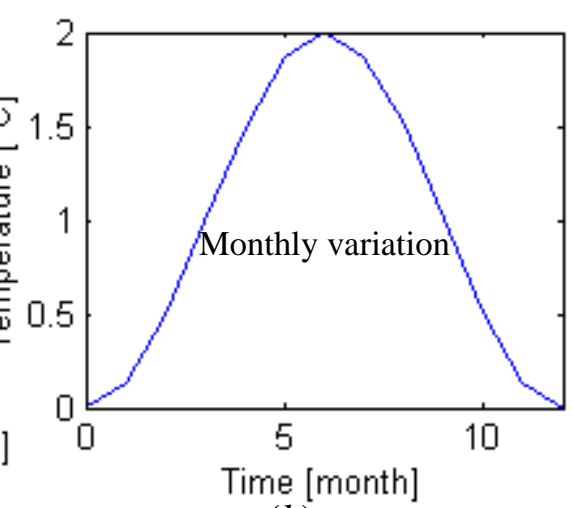

(b)

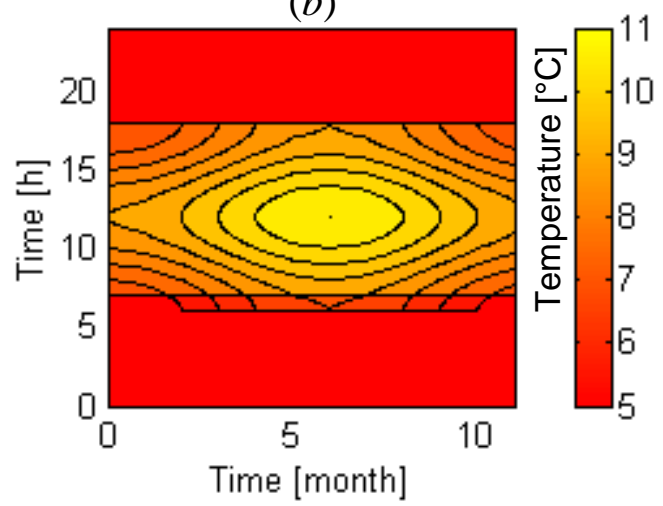

$(d)$

Fig. 1 Hourly and monthly difference between the indoor air temperature of a free-running building and the outdoor air temperature: $a$ ) 3D representation, $b$ ) monthly variation, $c$ ) hourly variation, $d$ ) cumulative effects of monthly and hourly variations.

\subsection{Adaptive comfort}

The thermal comfort exhibits a neutral zone. In Fig. 2, this zone is delimited by a lower, $T_{c l}$, and an upper comfort limit, $T_{c l}$. These limits vary with the mean outdoor temperature, resulting in an adaptation of the comfort criteria to the season. It is argued that thermal comfort in naturally ventilated buildings has larger seasonal differences than assumed by ISO 7730 and ASHRAE 55 Standards [4-8].

\subsection{Domains for heating, cooling and ventilation}

Using the indoor temperature of the free running building, the outdoor temperature and the comfort zone, the domains for heating, cooling and ventilation can be expressed by binary 
value functions (Fig. 2). Heating is needed when the free-running temperature is below the lower limit of comfort zone,

$$
\delta_{h}=\left\{\begin{array}{l}
1, \text { when } T_{f r}<T_{c l} \\
0, \text { otherwise }
\end{array}\right.
$$

Mechanical cooling is needed when both outdoor temperature and free-running temperature are larger than the upper limit of comfort zone:

$$
\delta_{c}=\left\{\begin{array}{l}
1, \text { when } T_{f r}>T_{c u} \text { and } T_{o}>T_{c u} \\
0, \text { otherwise }
\end{array}\right.
$$

Ventilation may be used in between heating and cooling. When mechanical or natural ventilation supply larger airflow rates than the minimum needed for indoor air quality, the indoor temperature may be varied from $T_{f r}$ to $\max \left(T_{o}, T_{c l}\right)$. This solution may be applied in situations corresponding to zones 3,4 and 5 of Fig. 2. In zone 5 , if the building were maintained tight, then mechanical cooling would be needed. But, by using ventilation, the indoor temperature may be decreased by increasing the airflow, approaching the outdoor air temperature if the air exchange becomes very large. By controlling the airflow rate, the indoor temperature may be varied in the interval defined by the temperature for free-running building (that corresponds to the situation when the building is tight) and the outdoor temperature. Zone 5, defined by:

$$
\delta_{f c}=\left\{\begin{array}{l}
1, \text { when } T_{o} \leq T_{c u} \text { and } T_{f r}>T_{c u} \\
0, \text { otherwise }
\end{array}\right.
$$

corresponds to mechanical cooling saved by ventilation (or free-cooling).

\subsection{Frequency distribution of degree-time for heating, cooling, and ventilation}

Similarly to the bin method used for building energy analysis [1], a measure of suitability of a climate may be obtained using probability distribution of outdoor temperature and the domains defined in Fig. 2. The daily variation of $T_{f r}$ as a function of $T_{o}$ may be defined for a time interval, typically 1 or 3 hours. Then, the product between a temperature difference (defined for heating, ventilation or cooling) and the probable frequency of this difference, $N \cdot T_{b i n} \cdot P_{d f}\left(T_{o}\right)$, gives a probability distribution. Its unit of measure is degree-time, where time has the value of the time interval (typically 1 or 3 hours).

The probability density is the limit of relative density when the number of values of the variable is infinity:

$$
\operatorname{Pr}=\lim _{N \rightarrow \infty}\left(\frac{f}{N}\right)
$$


For a discrete distribution having bins of $T_{b i n}$, the probability of the temperature being in the interval $T-T_{b i n} / 2$ and $T+T_{b i n} / 2, T \in\left\{T_{\min }, T_{\min }+T_{b i n}, T_{\min }+2 T_{b i n}, \ldots\right\}$ is:

$\operatorname{Pr}\left(T, T \in\left[T-T_{b i n} / 2, T+T_{b i n} / 2\right]\right)=T_{b i n} \cdot P_{d f}(T)$.

The probable frequency of variable $T$ of being in the bin $\left[T-T_{b i n} / 2, T+T_{b i n} / 2\right]$ is:

$$
f(T)=N \cdot T_{b i n} \cdot P_{d f}(T) .
$$

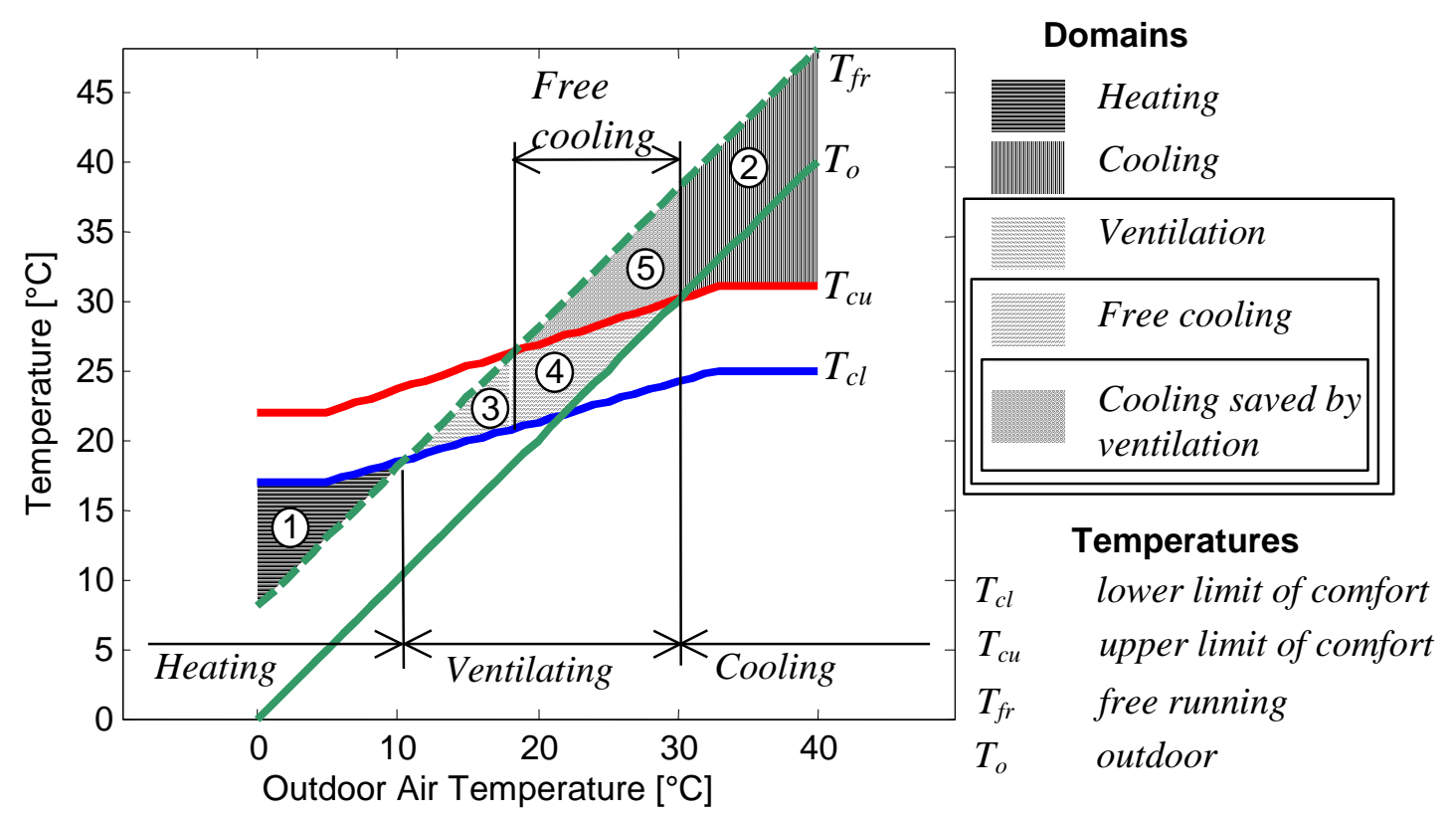

Fig. 2 Heating, ventilating and cooling domains.

Zone 1 of Fig. 2 is related to the energy needed for heating. The probability distribution of degree-time for heating is:

$$
f_{h}\left(t, T_{o}\right)=N \cdot T_{b i n} \cdot P_{d f}\left(T_{o}\right) \cdot\left(T_{c l}-T_{f r}\right) \cdot \delta_{h} .
$$

Zone 2 is related to the energy needed for cooling. The probability distribution of degreetime for cooling is:

$f_{c}\left(t, T_{o}\right)=N \cdot T_{b i n} \cdot P_{d f}\left(T_{o}\right) \cdot\left(T_{f r}-T_{c u}\right) \cdot \delta_{c}$.

Zone 5 is related to the energy saved for cooling by using ventilation. The frequency distribution of degree-time of free-cooling is:

$f_{f c}\left(t, T_{o}\right)=N \cdot T_{b i n} \cdot P_{d f}\left(T_{o}\right) \cdot\left(T_{f r}-T_{c u}\right) \cdot \delta_{p c} \cdot$ 
The large air exchange rate needed in this case may be achieved by using mechanical or natural ventilation. It is interesting to estimate if the driving forces for natural ventilation are available.

\subsection{Frequency distribution of degree-time for stack effect}

Natural ventilation is driven by wind pressure and buoyancy. Climatic suitability to the use of buoyancy driven natural ventilation may be assessed from stack pressure difference between two vertical openings separated by a vertical distance $h$ :

$$
\Delta p_{s}=\rho_{i} g h\left(T_{i}-T_{o}\right) / T_{o}
$$

where:

$\Delta p_{s}$ pressure difference due to stack effect, $\mathrm{Pa}$

$\rho$ air density, $\mathrm{kg} / \mathrm{m}^{3}$

$g$ gravitational constant, $9.81 \mathrm{~m} / \mathrm{s}^{2}$

$h$ vertical distance, $\mathrm{m}$

$T$ average absolute temperature, $\mathrm{K}$

subscripts

$i$ inside

$o$ outside.

The stack effect is proportional to $\left(T_{c u}-T_{o}\right) / T_{o}$. This expression may be simplified to $T_{c u}-T_{o}$ with an error less than $5 \%$ for the temperature range in which ventilation is applied. The frequency distribution of $\left(T_{c u}-T_{o}\right) / T_{o}$ or $T_{c u}-T_{o}$ gives a measure of the applicability of stack effect:

$$
f_{s e}\left(t, T_{o}\right)=N \cdot T_{b i n} \cdot P_{d f}\left(T_{o}\right) \cdot\left(T_{c u}-T_{o}\right) / T_{o} \cdot \delta_{f c}
$$

or

$$
f_{s e}\left(t, T_{o}\right)=N \cdot T_{b i n} \cdot P_{d f}\left(T_{o}\right) \cdot\left(T_{c u}-T_{o}\right) \cdot \delta_{f c} .
$$

Frequency distribution of degree-hour for heating, cooling, and cooling saved by ventilation allows us to assess the climatic suitability of an HVAC solution to a site. The frequency distribution of degree-hour of stack-effect gives an indication of the applicability of buoyancy driven natural ventilation. 


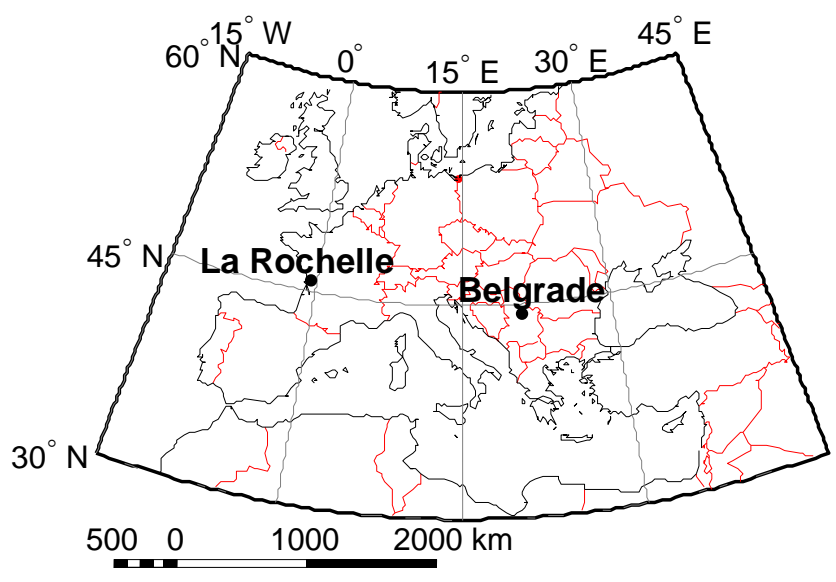

Fig. 3 Map showing the locations of two different sites for which the climatic suitability of HVAC is evaluated and compared.

Table 1 Annual degree-hours at 0, 6, 12 and $18 \mathrm{~h}$ for two locations around $45^{\circ} \mathrm{N}$ latitude.

\begin{tabular}{lrrrrr}
\hline & \multicolumn{4}{c}{ Hour } & \multicolumn{1}{c}{ Total } \\
\cline { 2 - 5 } & 00 & 06 & 12 & 18 & \\
\hline Heating & & & & & \\
\hline La Rochelle & 1560 & 1631 & 350 & 770 & $\mathbf{4 3 1 1}$ \\
Belgrade & 2883 & 2738 & 1059 & 1871 & $\mathbf{8 5 5 1}$ \\
& & & & & \\
Cooling & & & & & \\
\hline La Rochelle & 0 & 0 & 73 & 53 & $\mathbf{1 2 6}$ \\
Belgrade & 0 & 0 & 171 & 3 & $\mathbf{1 7 4}$ \\
& & & & & \\
Free-Cooling & & & & & \\
\hline La Rochelle & 5 & 2 & 670 & 306 & $\mathbf{9 8 3}$ \\
Belgrade & 0 & 12 & 708 & 213 & $\mathbf{9 3 3}$ \\
& & & & & \\
Stack-effect & & & & & \\
\hline $\begin{array}{l}\text { La Rochelle } \\
\text { Belgrade }\end{array}$ & 20 & 14 & 983 & 464 & $\mathbf{1 4 8 1}$ \\
\hline
\end{tabular}



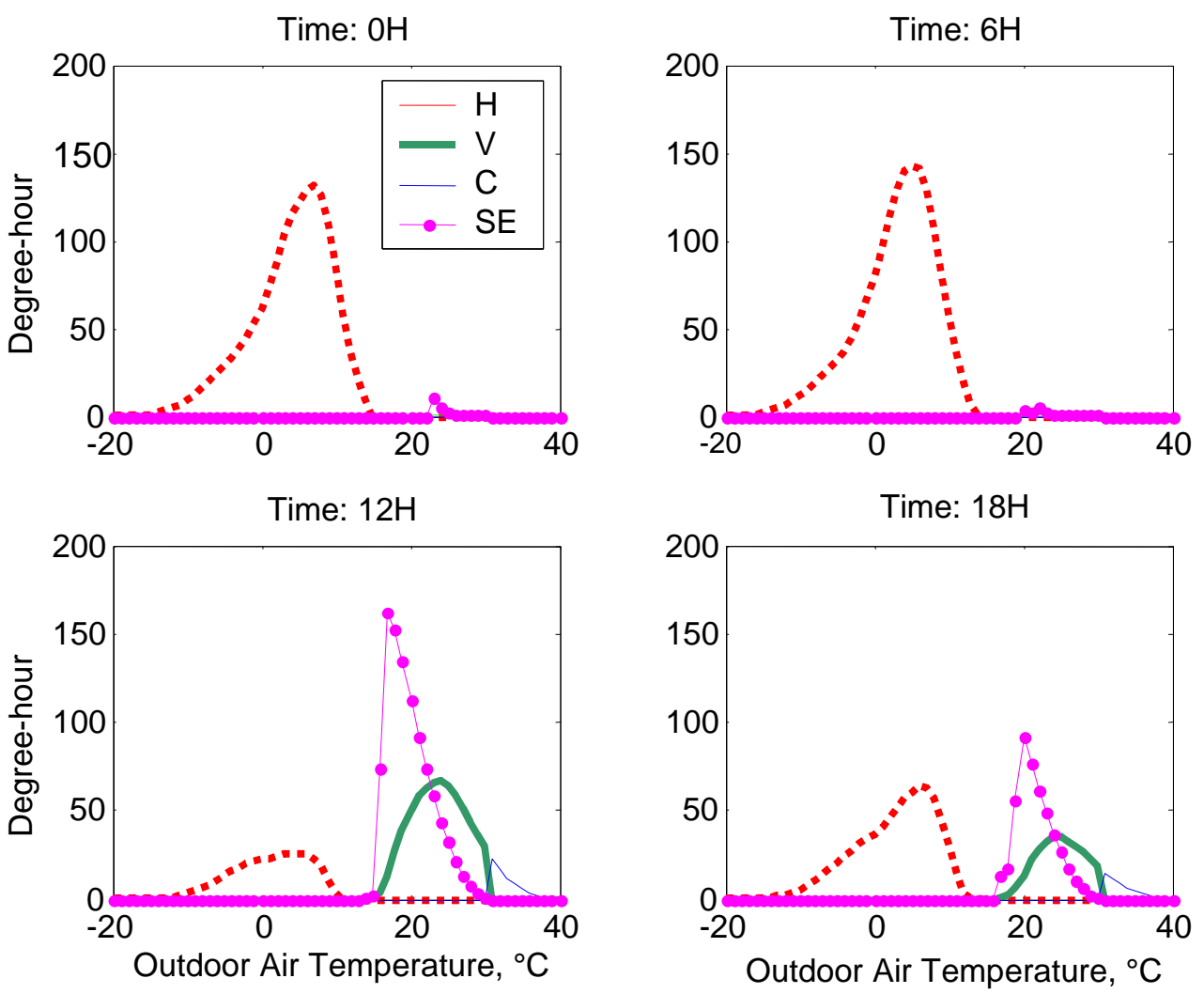

Fig. 4 Frequency distribution of degree-hour for heating $(\mathrm{H})$, cooling $(\mathrm{C})$, free-cooling by ventilation (V) and stack effect (SE) for La Rochelle, France.
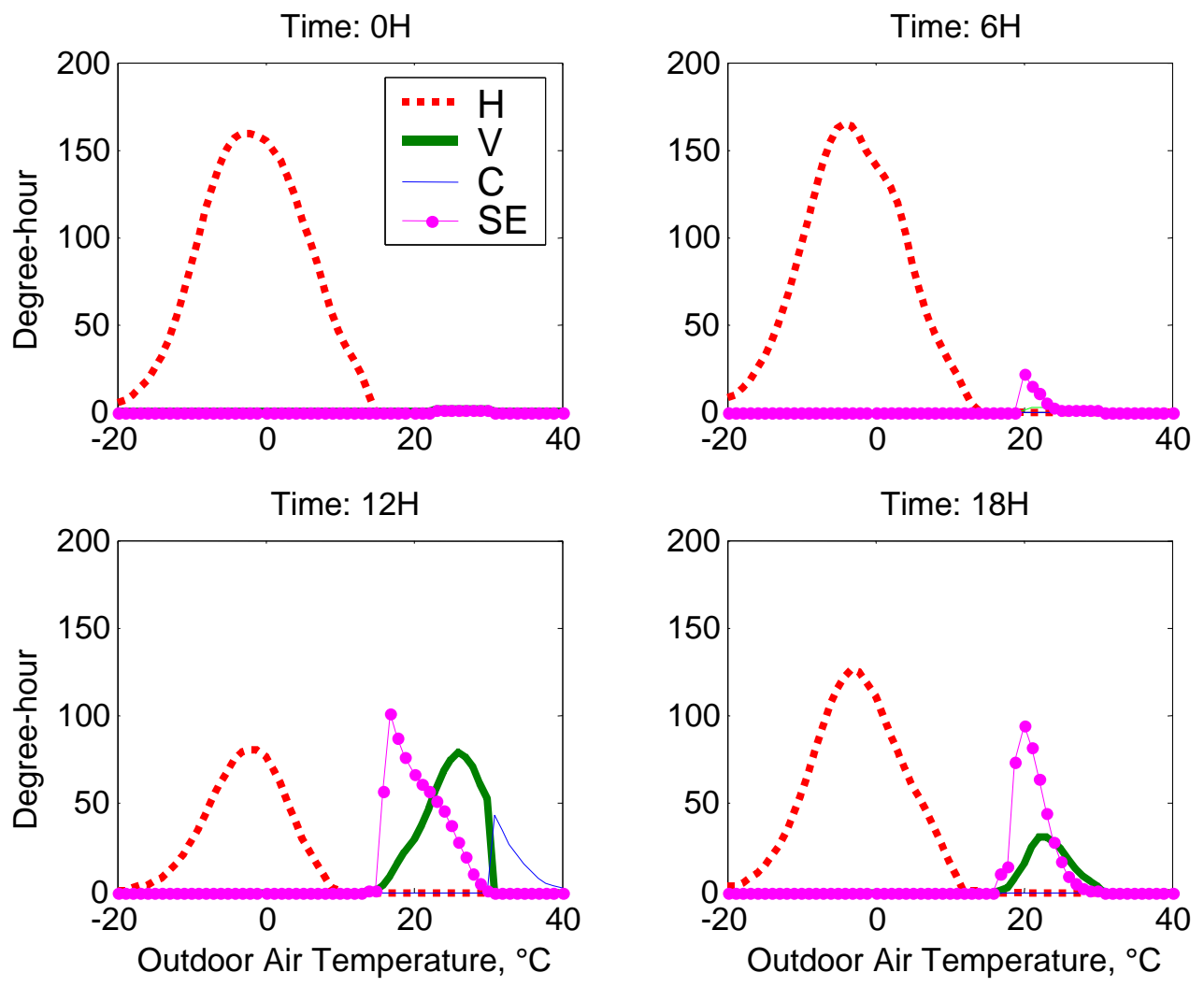

Fig. 5 Frequency distribution of degree-hour for heating $(\mathrm{H})$, cooling $(\mathrm{C})$, free-cooling by ventilation $(\mathrm{V})$ and stack effect (SE) for Belgrade, Yugoslavia 


\section{Interpretation of results}

Knowing the indoor temperature of the free-running building, the comfort criteria and the hourly outdoor temperature distribution, we can calculate the frequency distribution of degree-hour for heating and cooling. In this respect, the method presented in the previous section is analogous to bin method. In addition, we obtain information regarding the outdoor temperature for which the heating and cooling systems should have the maximum efficiency. Another important information obtained concerns the energy saved for cooling when ventilation is used and the suitability of buoyancy induced natural ventilation. This approach may be used to assess the climatic suitability of a new building to a site or to compare the performance of a given building in two different locations.

In order to illustrate the interpretation of the results, let us consider a building characterised by the difference between the outdoor temperature and the indoor temperature in free-running given in Fig. 1, and the adaptive comfort given in Fig. 2. For this building, let us consider two locations along the $45^{\circ} \mathrm{N}$ latitude: La Rochelle, France and Belgrade, Yugoslavia (Fig. 3 ). The results of frequency distribution of degree-hour for heating, cooling, cooling by ventilation and stack effect are given in Fig. 4 and Fig. 5. Their integrals over a year are given in Table 1.

Concerning the heating, we may notice that the energy demand for the considered building is twice as larger in Belgrade as in La Rochelle (Table 1). A properly designed heating system should have the maximum efficiency when the outdoor temperature is about $5^{\circ}$ at La Rochelle and $-5^{\circ}$ at Belgrade. In La Rochelle, the heating demand is much larger during the night than during the day, an important feature for buildings that do not need heating during the nigh (such as office buildings).

Regarding the cooling, we may observe that the totals are very similar (Table 1); however, the frequency distributions are different. In La Rochelle, the distribution is more dispersed over the day than in Belgrade (compare Fig. 4 and Fig. 5 at $12 \mathrm{H}$ and at $18 \mathrm{H}$ ). Consequently, if a cooling system would be considered, its installed power in Belgrade should be about twice higher than in La Rochelle. Moreover, if a buoyancy-driven natural ventilation solution would be envisaged, the stack effect at noon would be about 1.5 more important in La Rochelle than in Belgrade. In both locations, solely buoyancy driven natural ventilation cannot be used for cooling on the whole outdoor temperature domain. To avoid mechanical cooling, an alternative would be to change the thermal capacity of the building in order to obtain a time lag between the maximum outdoor and indoor temperatures.

\section{Climatic data}

The method presented above allows us to assess the climatic suitability when we know the thermal characteristics of the building (the indoor temperature of the free-running building), the thermal comfort zone, and the weather data (the probability density function of outdoor temperature). The indoor temperature in free-running can be calculated for new buildings or easily measured for existing ones. The comfort zone is a design requirement. The weather data may be obtained from local weather stations. As an alternative, average monthly temperature may be obtained from the Global Resource Information Database (GRID) centre from Geneva, a member of the United Nations Environment Programme (UNEP) global network of environmental information centres. Mean and standard deviation of temperature 
for every month at 3 hour intervals may be procured from International Satellite Land Surface Climatology Project (ISLSCP) Initiative.

The GRID database is intended to assist decision-making related to resource management and environmental planning. The data used in the implementation of this method is the Climate Database version 2.1 that was created at the International Institute for Applied System Analyses (IIASA) Laxenburg, Austria [9]. The weather records for at least five years during the period between 1930 and 1960 from up to eight different sources were standardised, ranked in quality, selected, interpolated and smoothed to fit a one-half degree latitude/longitude terrestrial grid surface (there are no values for non-land areas). The IIASA Climate Database is considered appropriate for use at least at regional scales, despite certain data gaps and inconsistencies.

Mean and standard deviation of temperature for every month at 3 hours intervals may be obtained from the database of the International Satellite Land Surface Climatology Project (ISLSCP) Initiative. The original data set was represented on a $320 \times 160$ grid, with a regular spacing of 1.125 degrees (lat./long.) between points along each row for the period January 1 , 1987 - December 31, 1988. The global atmospheric data are assimilated data resulting from the combination of atmospheric observations and model calculations. No surface observations are used, so that the surface data comes from the model simulations of surface processes, strongly constrained by observed atmospheric information and "a priori" surface climatological information.

\section{Conclusions}

Climatic suitability of a HVAC solution depends on building thermal behaviour, thermal comfort criteria and climate. In the early stages of design, the interest consists in deciding on general solutions based on few data. The indoor-outdoor temperature difference for the building in free-running is a synthetic characterisation of the thermal behaviour of the building. This temperature difference may be easily measured for existing buildings, or estimated for new buildings. The suitability of the climate to the use of ventilation for cooling depends on the energy saved for mechanical cooling. If buoyancy-driven natural ventilation is considered as a solution, then the presence of stack-effect may be assessed. The energy saved may be estimated by using the frequency distribution of the difference between the indoor temperature of the free running building and the upper limit of the comfort zone. If we admit that a building has the same thermal characteristics in two different sites, the frequency distribution of specific temperature differences gives us a measure of the climatic suitability.

\section{Acknowledgements}

This work was supported by the European Regional Development Fund (ERDF/FEDER) and by the European Commission who partially funded the project "URBVENT - Natural ventilation in urban areas" in the $5^{\text {th }}$ Framework Programme on research and technological development. The support of J. Axley, who spent a sabbatical year at the University of La Rochelle, partially funded by the Poitou-Charentes Region, is acknowledged with thanks. 


\section{References}

1. $* * *$, ASHRAE Handbook Fundamentals. 1993, Atlanta: ASHRAE.

2. Hong, T., S.K. Chou, T.Y. Bong, Building simulation: an overview of developments and information sources. Building and Environment, 2000. 35: p. 347-361.

3. Axley, J., Application of Natural Ventilation for U.S. Commercial Buildings. 2001, NIST. p. 146.

4. Nicol, F.J. Characterizing occupant behaviour in buildings: towards a stochastic model occupant use of windows, lights, blinds, heaters and fans. in Seventh International IBPSA Conference. 2001. Rio de Janeiro, Brazil.

5. Sayigh, A., A. H. Marafia, Thermal comfort and the development of bioclimatic concept in building design. Renewable and Sustainable Energy Reviews, 1998. 2(1-2): p. 3-24.

6. Fountain, M., G. Brager, R. deDear, Expectations of indoor climate control. Energy and Buildings, 1996. 24: p. 179-182.

7. de Dear, R., Adaptive thermal comfort in natural and hybrid ventilation. 1999, International Energy Agency, Annex 35 Energy conservation in buildings and community systems: Sydney, Australia.

8. Brager, G., R. de Dear, Thermal adaptation in the built environment: a literature review. Energy and Buildings, 1998. 27: p. 83-96.

9. Leemans, R., W. Cramer, The IIASA database for mean monthly values of temperature, precipitation and cloudiness of a global terrestrial grid.. 1991, International Institute for Applied Systems Analysis: Laxenburg, Austria. 